\title{
Exploring imagination as a methodological source of knowledge: painting students' intercultural experience at a UK university
}

DOI:

10.1080/1743727X.2020.1796958

\section{Document Version}

Accepted author manuscript

Link to publication record in Manchester Research Explorer

Citation for published version (APA):

Huang, Z. M. (2020). Exploring imagination as a methodological source of knowledge: painting students' intercultural experience at a UK university. International Journal of Research and Method in Education, 1-13. https://doi.org/10.1080/1743727X.2020.1796958

\section{Published in:}

International Journal of Research and Method in Education

\section{Citing this paper}

Please note that where the full-text provided on Manchester Research Explorer is the Author Accepted Manuscript or Proof version this may differ from the final Published version. If citing, it is advised that you check and use the publisher's definitive version.

\section{General rights}

Copyright and moral rights for the publications made accessible in the Research Explorer are retained by the authors and/or other copyright owners and it is a condition of accessing publications that users recognise and abide by the legal requirements associated with these rights.

\section{Takedown policy}

If you believe that this document breaches copyright please refer to the University of Manchester's Takedown Procedures [http://man.ac.uk/04Y6Bo] or contact uml.scholarlycommunications@manchester.ac.uk providing relevant details, so we can investigate your claim.

\section{OPEN ACCESS}




\title{
Exploring imagination as a methodological source of knowledge: Painting students' intercultural experience at a UK university
}

\section{Zhuo Min Huang}

\begin{abstract}
Imagination, as an essential aspect of human nature, is fundamental to all ways of thinking. However, this powerful faculty is usually overlooked or marginalised in educational research. In the article, I explore imagination as a methodological source for researchers to generate expansive, purposeful, fluid, and developmental knowledge about the subjective realities constructed by individuals as meaning-makers. To do so, I illustrate how I use two variations of painting (i.e. cartoon- and freestyle- painting) to facilitate such an imaginative space for understanding students' meaning-making about intercultural experience. Imagination, as facilitated through the subjective, transformative space of arts methods, can extend the epistemological and methodological possibilities of knowledge for educational research. It provides a post-qualitative methodology which can be particularly useful for enabling conceptually-abstract and structurally-complex knowledge that may not be expressible or interrogatable in a coherent way through traditional research methods in education.
\end{abstract}

Keywords: imagination, arts methods, intercultural experience, painting, knowledge

\section{Introduction}

In this article, I discuss how I use imagination as a methodological source of knowledge to understand students' meaning-making of intercultural experience at an internationalised UK university. In this context, students face opportunities and challenges to interact with people from different cultural backgrounds and to engage with diverse ways of living and being (i.e.

Huang, Z. M. (2020). Exploring imagination as a methodological source of knowledge: Painting students' intercultural experience at a UK university. International Journal of Research \& Method in Education. 
cultures). In order to develop an in-depth understanding of students' subjective constructions of such intercultural experiences, I use painting to enable an imaginative space of knowledge for research. Below, I first introduce my understanding of the term 'imagination'. Then, I discuss the interplay between imagination and the arts in educational research. After this, I introduce my use of painting, and present some example paintings in order to illustrate imagination as a methodological source of knowledge. Finally, I explore four benefits of imagination for educational research, including the potentials of imagination to encourage expansive, purposeful, fluid, and developmental knowledge for understanding the subjective realities constructed by individuals.

\section{Imagination}

The word 'imagination', originated from the Latin verb 'imaginari', refers to 'picturing to oneself' and 'forming and manipulating images' (Eve, 2015). The etymological root of the term implies the symbolic power of 'image' as fundamental to imagination (Barth, 2001; Bland, 2012). This power of 'image' is captured by the Chinese term of imagination - i.e. 想 象/xiăng xiàng- which could be translated in English as 'thinking of the image of an elephant' (Li, 2009). 想象/xiăng xiàng reflects the psychological process of using perceptual materials to (re)create the mental image of something (e.g. an elephant) without requiring its physical presence. In other words, imagination could empower the mind to suppose the possible of the impossible by mentally visualising things that are not actually present. It transcends beyond the limit of the present existence and enables the mind to conceive what

Huang, Z. M. (2020). Exploring imagination as a methodological source of knowledge: Painting students' intercultural experience at a UK university. International Journal of Research \& Method in Education. 
could be and might be (Barrow, 1988; Hanson, 1988). Through the power of imagination, individuals can make meaningful connections across diverse trajectories of the mind (e.g. memories of the past, visions for the future, and perceptual experiences of the present) (Keightley and Pickering, 2012) and decode personalised understandings of their experiences (Warnock, 1976).

The term 'imagination' has, however, been used in various ways, each with their own emphasises (Stevenson, 2003). It sometimes refers to the ability to create and entertain mental-images. For instance, Epstein (2004), following Langer (1953), discusses how imagination creates 'image-schematic conceptual representations' through meaning-making processes that symbolically transforms and constructs individuals' experiences (256). Imagination also sometimes refers to the ability to conceive non-existence - i.e. something that is not actually happening here and now, but which is possible in the inner world (e.g. mentally seeing, hearing, or feeling) (e.g. Barrow, 1988, 81). Thus, imagination is sometimes discussed as something opposite to reality. It could refer to a non-rational operation of the mind which thinks of fictional things or fantasies (e.g. Kast, 2014; Walton, 1990), and which is opposite to reason and rationality (Stevenson, 2003).

However, scholars such as Iheoma (1993) argue that seeing imagination simply as non-rational fantasies could downplay the higher-order thinking potential of imagination and reinforce the privileged status of rationality and reasoning as the only credible vehicle of knowledge. In order to legitimise imagination as a credible source of knowledge, Barrow 
(1988) suggests that imagination is bounded with logic and abstract conceptions, which themselves are a form of rationality. Moreover, Iheoma (1993) rejects the traditional antinomy between imagination and reasoning. He suggests that imagination, as a 'creative faculty' of manipulating mental imageries and symbolic meanings, is fundamental to all processes of thinking (49) such as rational thoughts, emotions, hope, and morality. It provides an all-embracing psychological mechanism, and constitutes a source of 'poetic wisdom' where all human knowledge and civilisations originate from $(45,47)$. Therefore, imagination can be seen as 'the ability to think of anything at all' (Stevenson, 2003, 245). It transcends human understandings beyond the 'immediately obvious' of the world (273), and captures human beings not only in terms of what they see, but also what they want to see, and not only in terms of how they live, but also how they want to live (Gokbulut and Kus, 2019).

Only through the ability of imagination can we make sense and form subjective impressions of the otherwise meaningless environment, and move beyond simply 'vacuuming up' whatever happens around us. Imagination, therefore, provides a precondition for any experience at all (Kant, 2000, 113). It transforms random exposures into personalised perceptions of experiences (Pelaprat and Cole, 2011, 339) through a 'gap-filling' process (Vygotsky, 2004). In this process, imagination connects the organic, fragmented exposures in ways that contribute to resolving the gaps between the self, others, the past and the present, and between subjective reality and the world (Pelaprat and Cole, 2011, 399, 413). Imagination maintains our ability of using the abstract, fluid, invisible agent 'I' (Glas, 2006). We can, thus, continue thinking, feeling, behaving and living as the person who we are, and 
connect our 'I' across time and space (ibid). We can also think of others, communities and societies, and relate our fluid 'I' to them (Kanno and Norton, 2003, 241). Therefore, imagination is a fundamental unit of our lived experience, allowing us to create 'my experience', and articulate the subjective reality of the world that we live in (Bolton, 1982; Boyce and Greer, 2013, 107). It sustains the symbolic work of constructing the lived experience - a project of coming to know about the self and the world (Dryden, 2004). Therefore, imagination can provide a source and means of knowledge (Kind and Kung, 2016, 113) for researchers to understand individuals' subjective construction about their experience and becoming.

In the following sections, I adopt imagination as fundamental to all thinking and experience. I use imagination as methodological source to understand students' meaning-making about their intercultural experiences at a UK university. I see students' intercultural experiences as subjectively transformed and recreated - for which I will use the word 'transcreated' - through imagination; which may be contrasted with a collection of what happened around them in the UK HE environment. Having discussed my understanding of imagination, I discuss the imaginative space provided by the arts below.

\section{The imaginative space of the arts for educational research}

The power of imagination is consistent with the nature of the arts. The arts are a selective (re)creation of symbolic meanings beyond present existence as shaped by the subjective reality of the artist or audience (Kamhi and Torres, 2000, 26). Both the arts and imagination

Huang, Z. M. (2020). Exploring imagination as a methodological source of knowledge: Painting students' intercultural experience at a UK university. International Journal of Research \& Method in Education. 
provide transformative power for thinking and becoming, through which individuals can transcend their understandings of present existence and the taken-for-granted (Halpin, 2007), and explore the possibilities of alternative realities. Therefore, both the arts and imagination are filled with subjectivity and intentionality, and are not merely nouns but actions to engage with (Sullivan, 2008, 241). The arts are made and responded to through imagination, and thus, rely on imagination as a powerful source of knowledge (Kant, 2000, xxvi). The arts also complement imagination by providing a tangible form to fluid, invisible, and private mental imageries (Sullivan, 2010). In this way, the imaginative source of knowledge becomes externally expressed and accessible through the activity of the arts (Dryden, 2004, 259). As imagination finds its expression and application through the arts, the arts also shape and develop the conscious experience of imagination. The harmonious interplay between the arts and imagination provides a thinking space for individuals to exercise their symbolic senses and to transcreate meanings about their subjective reality (Kant, 2000, xxvi).

Arts methods have been used in, and have contributed to redefining the know-ablity and methodological affordances of educational research, since the late 1970s (Eisner, 2006; Sinner et al., 2006). Rather than arriving at 'truthful' knowledge - an epistemology that prioritises certainty and aims to confirm predictions of similar future events, arts-based educational research (ABER) seeks to provide new insights and to raise questions rather than giving conclusive answers (Barone and Eisner, 2006, 96). By experimenting with non-linguistic forms of data, ABER provides a unique means for enhancing the perspectives of the ineffable aspects of experience in schools and universities (101). Painting, as a

Huang, Z. M. (2020). Exploring imagination as a methodological source of knowledge: Painting students' intercultural experience at a UK university. International Journal of Research \& Method in Education. 
visual-arts method, distinguishes itself from other arts methods (such as music or drama) by providing a tangible, timeless form to invisible, fluid thoughts (Sullivan, 2008, 244). It also epistemologically and methodologically de-essentialises language as the normalised or only legitimate source of knowledge. That is, painting provides an opportunity for researchers to embrace visual-arts-mediated imagination for creating knowledge about the subjective realities constructed by students. Thus, in the following, I adopt the imaginative space of painting (as illustrated in sections 4.2 and 4.3) to develop understandings of students' subjective learning from intercultural experience.

A considerable amount of attention has focused on legitimising the epistemic status of artistic knowledge over the last decade (e.g. Barone and Eisner, 1997; Barone, 2006; Eisner, 2006; McNiff, 2012). McNiff (2012) suggests that one of the biggest opportunities and challenges of arts-based research is getting researchers to 'believe in it' (5). I believe that getting researchers to 'believe in it' must go beyond seeing artistic knowledge as complementary to more established sources of knowledge in educational research. Such a complementary view may see arts methods used to uncover otherwise unavailable, hidden knowledge from disadvantaged groups - for instance, with children/young learners in order to assist their learning and expressions (e.g. Warwick and Purdy, 2019), or for the purpose of empowering the marginalised groups (e.g. Bauer et al., 2019). Although this can make valuable contributions to research, seeing artistic knowledge as complementary can distort and distract the scholarly work of ABER with the prior concerns of the quantitative paradigm or traditional qualitative methods. Artistic knowledge is distinct from the positivist paradigm 
which sees the only true knowledge as quantifiable and objective (Armitage, 2012). Framing ABER with claims of probability or plausibility may distract researchers from the purpose of arts methods for imaginatively experimenting and generating new understandings (Sullivan, 2008, 242).

In this paper, I do not adopt arts methods as an 'alternative', and merely for uncovering otherwise unavailable knowledge. Instead, I recognise that arts methods can provide an imaginative space (fundamental to all ways of thinking) (Stevenson, 2003) for educational researchers to develop knowledge about the subjective realities (e.g. experience, learning, perspectives or relationships) constructed by individuals as meaning-makers. I, thus, use painting as a visual-arts method to develop knowledge about students' meaning-making of intercultural experience at a UK university. My methodological design is different from existing studies about students' intercultural experience, which usually generated knowledge through students' responses to language-based methods such as interviews (e.g. Newsome and Cooper, 2016) or questionnaires (e.g. Lambert and Usher, 2013). By contrast, my arts-based design provides an imaginative space for researchers to generate data that goes beyond what students can immediately report or articulate (as in questionnaires and interviews). Instead, it facilitates arts-mediated imagination which can create knowledge based upon the students' experimentation, transcreation and demonstration of their meaning-making. This potential of arts-mediated imagination, and a focus on painting to imagine, is illustrated in the next section. 


\section{Painting to imagine}

Having discussed the imaginative space provided by the arts, in this section I illustrate how I use painting to facilitate an imaginative space of knowledge for me to understand students' meaning-making about their intercultural experience. Below, I first introduce my recruitment of the students. Then, I outline my use of two variations of painting activities. Finally, I exemplify the students' insights enabled through the imaginative space of painting.

\subsection{Participants}

In order to develop an in-depth understanding of students' meaning-making about their intercultural experience, I present data from four postgraduate students at a UK university. These students were originally selected, as part of a larger study (Huang, 2019), because they were a) interested in exploring the meanings about their intercultural experience, and b) comfortable with using creative-arts methods to make meanings. This means that the students did not have to be professional in, good at, or even familiar with the use of creative-arts, but needed to be open to use them for making meanings about their intercultural experience. I set these criteria in order to maximise my opportunity for generating rich insights about students' intercultural experience through the imaginative space of the arts. However, I am aware that my purposefully-selected participants might not be representative of the population of postgraduate students at the university. Additionally, I did not frame my recruitment of the students according to their nationalities or ethnicity - a common focus in studies about students' intercultural experience (e.g. Schweisfurth and Gu, 2009). Instead, I recruited four

Huang, Z. M. (2020). Exploring imagination as a methodological source of knowledge: Painting students' intercultural experience at a UK university. International Journal of Research \& Method in Education. 
students who were culturally-complex and culturally-unique individuals (Singer, 1998) (see their profiles in Table 1).

[Table 1 near here]

\subsection{Cartoon painting and free style painting}

I used two variations of painting, which I call 'cartoon painting' (e.g. Images 1 and 2) and 'freestyle painting' (e.g. Images 3 and 4), with the students in two individual (i.e. one-to-one) sessions. I recognise painting as both a process and a product (Sullivan, 2010) of imagination. Thus, I focus not only on the content of the painting, but also on the process of creating the painting. For instance, during the students' process of painting, I took observation notes about their sequences of paintings, their focuses on visualising particular symbols, their pauses and changes, and their autonomous narrations, body language, and facial expressions. After the students completed their painting, I first asked them to introduce it to me: 'Can you tell me about your painting?' Then, I asked them to make further meanings through the painting about their intercultural experience. For instance, I used prompts such as: 'During your painting process, I noticed ..., can you explain what happened by then?' or 'In your painting, can you tell me what ... (e.g. a symbol, colour, or structure) represents?'

In the first session ('cartoon painting'), I asked the students to create a simple cartoon about any aspect of their intercultural experience. Cartoons can provide quick access to key meanings through an efficient use of simple lines, shapes and colours, with no requirement for extensive artistic details (Gokbulut and Kus, 2019). It was, therefore, less intimidating for 
the students, who were not professional artists, to first create a simple cartoon rather than a full, complex painting. The students had 15 minutes to create the cartoon. We then, had a 30-minute discussion about the cartoon they had created.

In the second session, I asked the students to create a 'freestyle painting' in order to make further and more integrated, overall meanings about their intercultural experience. I used prompts such as: 'now we have created a simple cartoon about your intercultural experience. In this activity, you will have a bigger space to paint in any style that you like, about what your intercultural experience means to you'. The students had 30 minutes to create the freestyle painting, which was followed by a 30-minute discussion with me.

The two variations of painting both aimed to prioritise meanings (and meaning-making) beyond the form (e.g. drawing skills). By using painting, I generated a visual (i.e. the image) and accompanying verbal (i.e. the discussion about the painting) dataset of the students' meaning-making about their intercultural experience (Huang, 2017, 2019). In the next section, I present some example paintings of the students' in order to illustrate imagination as a methodological source of knowledge.

\subsection{Students'insights through the imaginative space of painting}

In order to illustrate the two variations of painting, I will discuss two examples of cartoon painting - i.e. 'The bubble' ${ }^{1}$ and 'They are all the same!', and two examples of freestyle painting - i.e. 'The fountain' and 'An intercultural eye'. These four paintings are not only

\footnotetext{
1 The paintings are named by me according to my understanding of what the students imagined in each painting.
} 
representative of the types of paintings generated by my larger study (Huang 2019), but also, I believe (based upon the analysis of a large number of paintings) (see Huang, 2017, 2019), can provide rich and clear examples to demonstrate the benefits of imagination as a methodological source of knowledge (as further discussed in Section 5).

\subsubsection{The bubble}

Image 1. The bubble

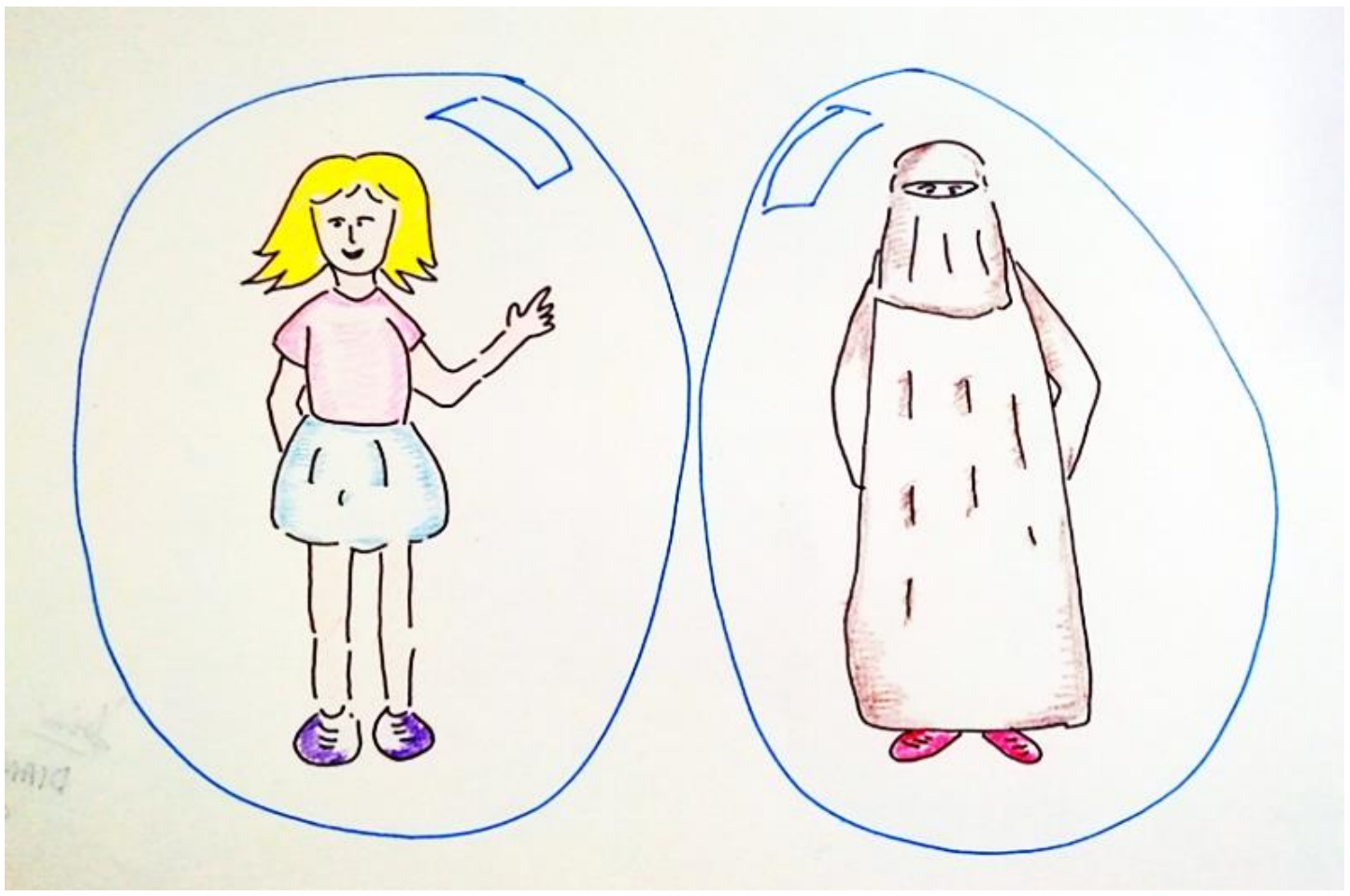

Ana made meanings about her intercultural experience through the imaginative space of "the bubble' (see Image 1). In her process of painting creation, she first drew two characters: a Western and a Muslim woman. Then, she added a bubble surrounding them individually. She introduced the cartoon painting as: people from different cultures have their own 'bubbles' . The bubble could be 'your culture, experience, language, and your interpretation of things'. 
Her purpose for painting the bubbles was, however, to 'break the bubbles to an extent' in order to enable connections and communications with people from different cultural backgrounds.

Through the imaginative space of painting, Ana extended her focus from the two women with different physical appearances to an awareness of the fluid, invisible complexities of their 'bubbles' in intercultural communication. She negotiated between existence and non-existence, and consequentially demonstrated a transition of thinking. Ana's imagination of the 'bubble' also enabled her to see critically beyond the stereotypes. This critical thinking was visualised, for instance, by a pair of striking red shoes under the black hijab of the Muslim woman. She said that she intentionally used this colour contrast to symbolise her imagination of the woman under the veil, who cannot be simply reduced into a dull, stereotypical image of Muslim women. I believe that Ana's meaning-making of the cartoon was enabled through what Bland (2012) calls 'applied imagination'. In this process, she used 'empathetic imagination' to develop understandings and compassion for others, and used 'critical imagination' to challenge the immediately obvious and available (e.g. stereotypes). Her 'creative imagination' also provides her useful, new ideas (e.g. breaking or connecting the bubbles) to change present existence.

Ana's imagination also enabled her to develop a conceptualisation of the bubble. She imagined a set of sub-signs (i.e. layers, thickness, colour, a non-static status and the air -inside and -outside) which I summarise below. First, Ana said that the bubble has layers 
which are individually developed and arranged, and contextually fluid for constituting who a person is in an intercultural context. Second, she suggested that each layer has different thickness which represents the level of difficulty to break a particular layer of the bubble and to connect a certain aspect of 'I' with others. Third, Ana recognised that all bubbles, regardless of their differences, share the same nature as visualised by the same blue colour of the bubbles. She suggested that the bubbles are essentially constituted by the same set of elements, such as one's language, culture, past experience, childhood, education, emotion, insecurity, vulnerability and responsibility.

Last but not least, Ana borrowed the reference of 'bubble' from nature, so to extend her imaginative source of knowledge. In nature, a bubble is unstable, and can remain, break, fly, or join with other bubbles. Ana imaginatively added such an instability to the cartoon, proposing that what bubbles in nature do may express alternative relationships of people. Also, in nature, a bubble is a spherical cavity with air both inside and outside, and this shapes and sustains the status of the bubble. Ana manipulated the symbolic meaning of the blank space inside and outside of the bubble in the cartoon. She imagined that the air-inside represents one's past experience and exposure, while the air-outside represents one's new exposure. She suggested that this represented the negotiation between the old and the new, the familiar and the unfamiliar, the known and the unknown, and the security and the insecurity that constitutes who a person is and what they do in relation to others in an intercultural context. Through the cartoon of the bubble, Ana obtained an imaginative space to know about non-existence (e.g. what could be and what might be). Her critical imagination 
pushed beyond the common focus of cultural differences in intercultural studies, and instead, explored the construct of situated, fluid persons in the intercultural context.

\subsubsection{They are all the same!}

Image 2. They are all the same!

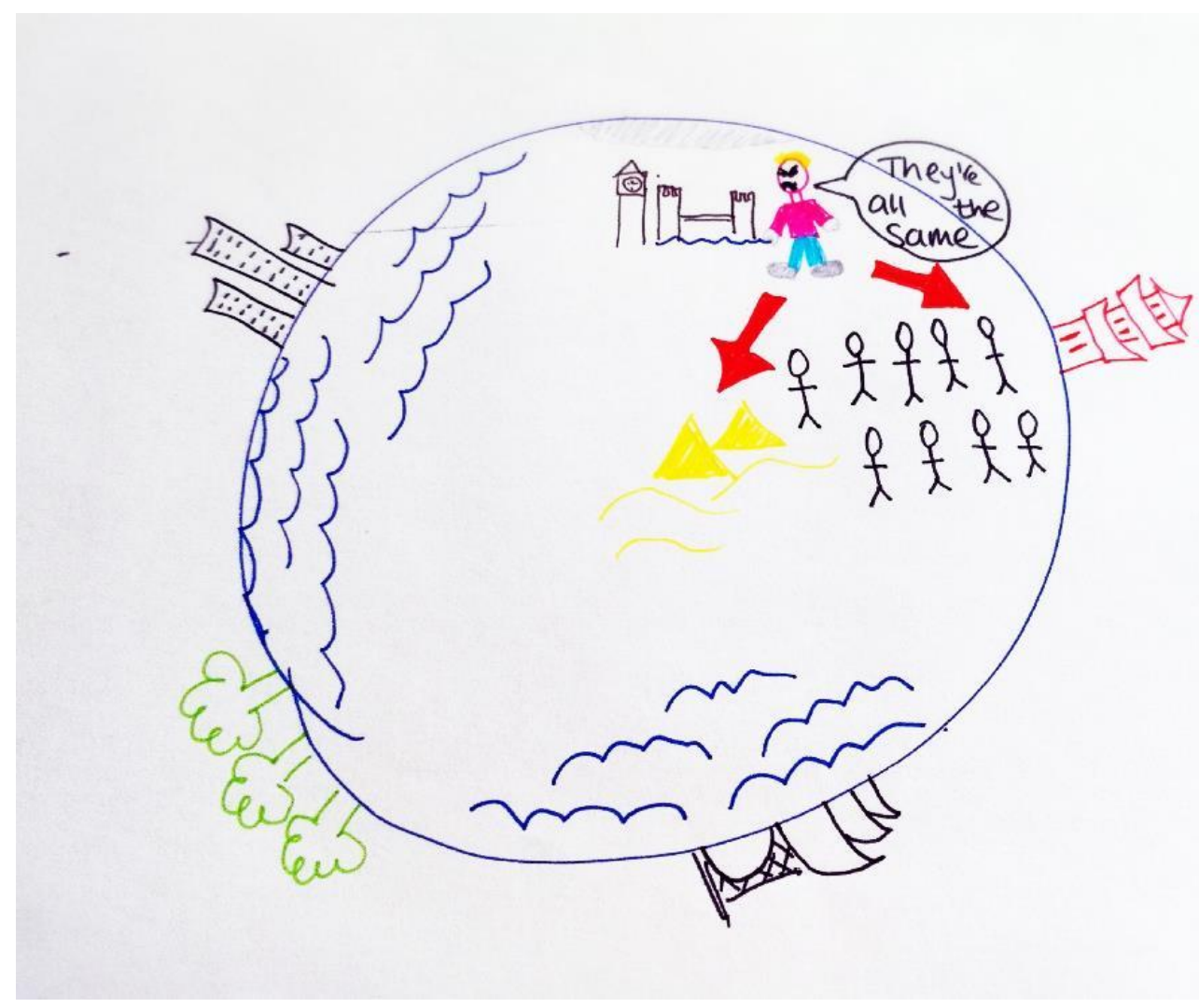

In Ellyn's cartoon painting 'They are all the same!' (see Image 2), she reflected upon the common issue of stereotyping and generalisation in intercultural communication. She used 'crazy colours' such as 'pink' and 'blue' to highlight the British person: 'this massive individual who is all really different' from others. Then, she drew the stick men on the earth. Through this contrast of bright and black colours, Ellyn problematised the essentialist, and reductionist perception of 'others' as if they were somehow 'robots' or 'clowns' who are all

Huang, Z. M. (2020). Exploring imagination as a methodological source of knowledge: Painting students' intercultural experience at a UK university. International Journal of Research \& Method in Education. 
the same. She reflected that such an idea of 'blank people bunched together' could have 'made it scarier to think about trying to communicate with them'. Through the imaginative space of the cartoon, Ellyn visualised and developed awareness of this potentially problematic mental world:

They are all the same!

They are all just like little dots on the map.

The West is huge [loud voice] and you got all these countries in there.

We think ourselves as being this individual.

But when you try to communicate with someone from their own culture, you think of that person almost is their whole culture.

It's like, oh god, I'm talking to this whole culture!

Ellyn's imagination of this problematic mental world had alerted her to the essentialist and reductionist dangers (Holliday, 2000) in intercultural communication. It also opened up a space for her to think about the process of stereotyping, a process that is usually driven by the lack of 'a real frame of reference' in one's intercultural experience and exposure.

\subsubsection{A fountain}

In Helios' freestyle painting 'The fountain' (see Image 3), he imagined the mechanism of a fountain in his intercultural experience. He used the mechanism of a fountain to reflect the circle of eco-self-(re)creation, a continuous and selective process of internalisation and externalisation in his intercultural experience. He said the heart-shaped water spray in the centre represents his being (i.e. who he is) and conduct (i.e. what he does) in intercultural

Huang, Z. M. (2020). Exploring imagination as a methodological source of knowledge: Painting students' intercultural experience at a UK university. International Journal of Research \& Method in Education. 
experience. The flows in various colours and shapes at the two sides of the painting represent the heterogeneous exposures of intercultural experience. These flows of exposures infuse into a filter (i.e. a black-brownish triangle) at the bottom of the painting, which provides the source for the fountain sprays.

Image 3. The fountain

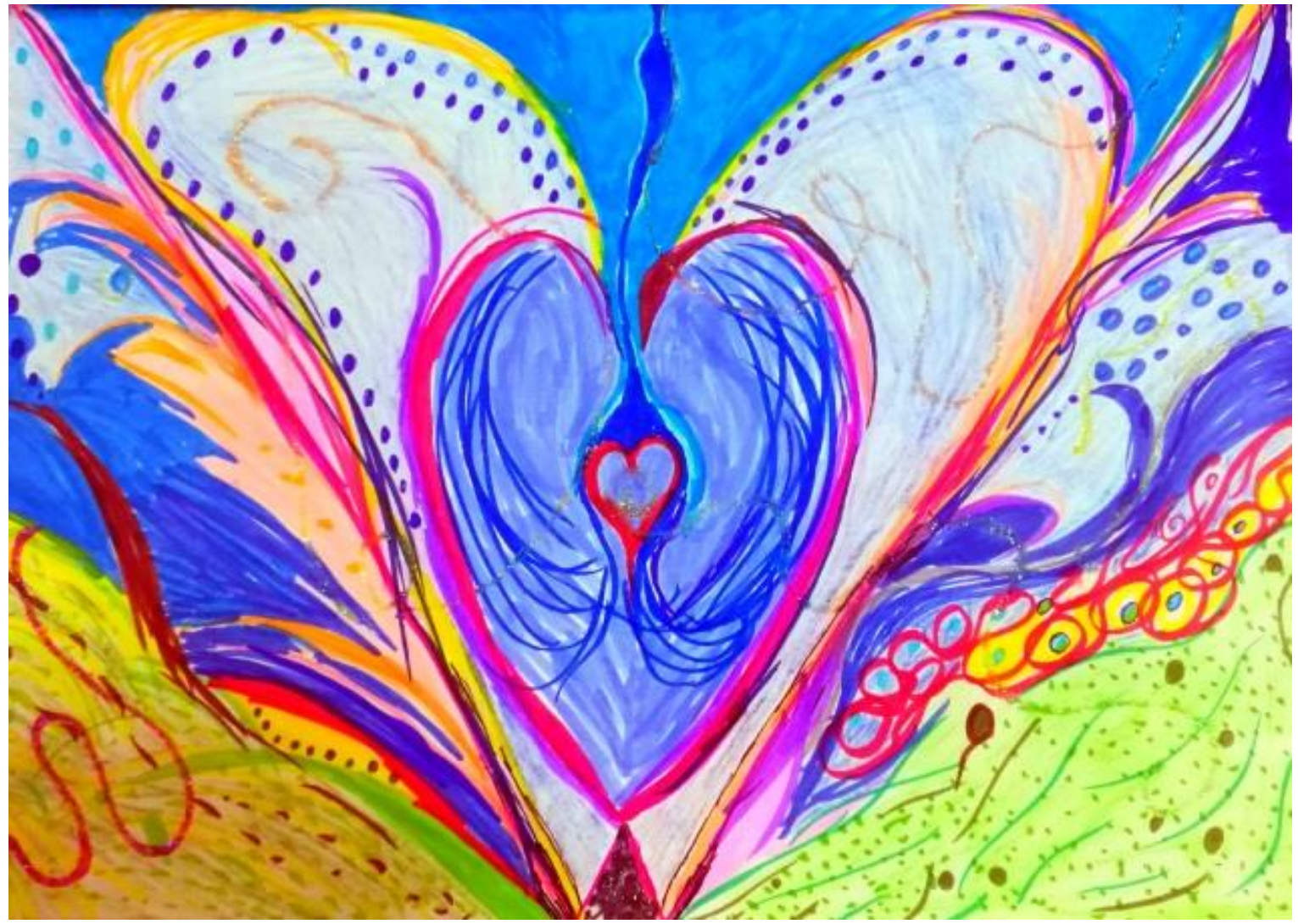

The filter constitutes a core element in Helios imagination of the fountain. He used a stable, solid, triangular shape for the filter. This shape, in contrast with the fluid and curvy strokes of the overall painting, allowed Helios to highlight the fundamental, structural role of agency in intercultural experience. With this agentive filter, a person can be intentional in the selective processes of internalisation and externalisation rather than uncritically 'taking in' all 
exposures. Through the imagination of the fountain, Helios gained a non-static space to make meanings about the circle of eco-self-(re)creation (i.e. becoming) through intercultural experience.

\subsubsection{An intercultural eye}

Image 4. An Intercultural eye

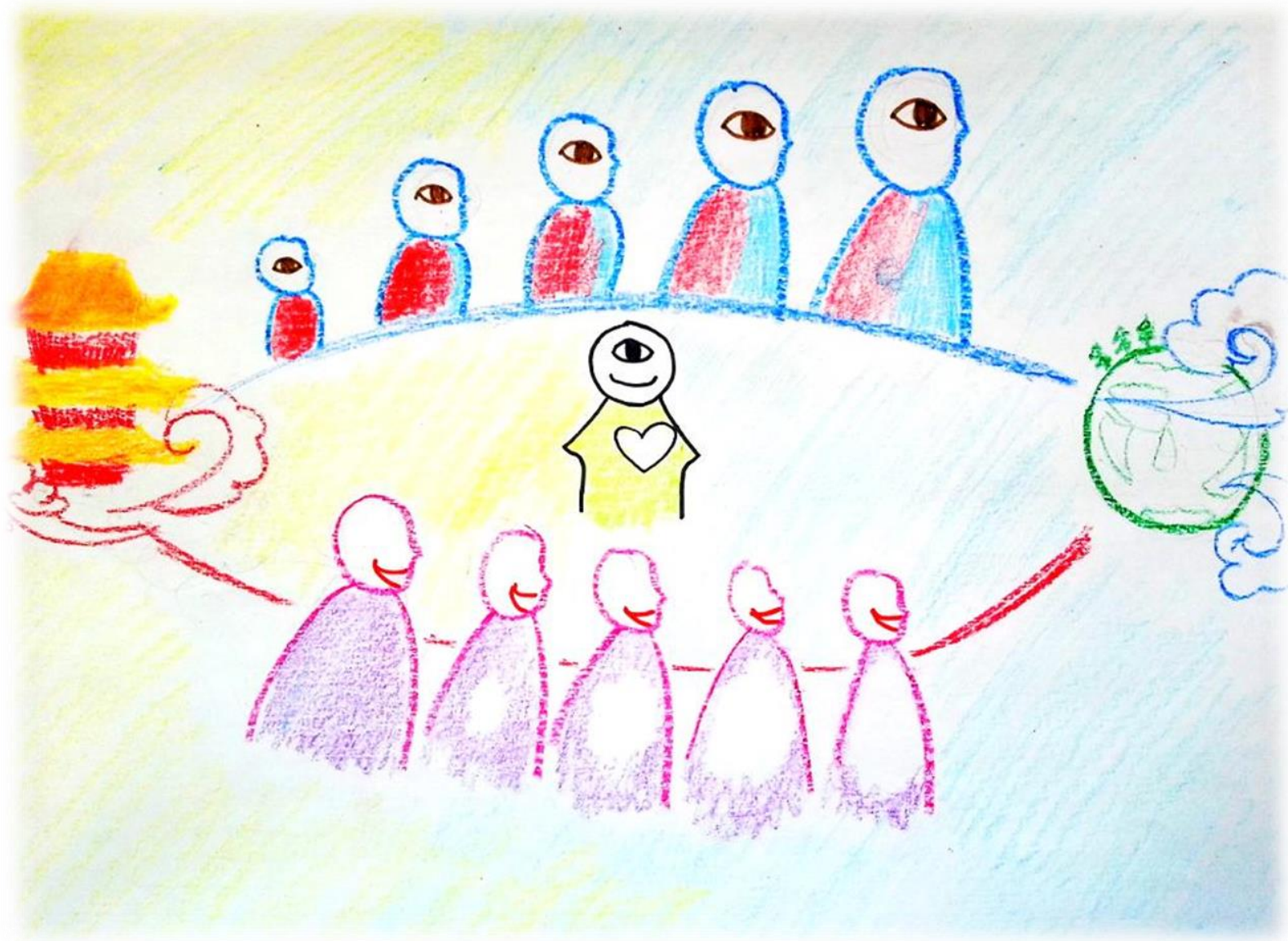

In Jiajia's free-style painting 'An intercultural eye' (see Image 4), she imagined her becoming through intercultural experience. She first anchored her imagination in-between two geographical locations: a traditional building representing her home country, and the earth representing the internationalised, multicultural environment at the university. Then, within

Huang, Z. M. (2020). Exploring imagination as a methodological source of knowledge: Painting students' intercultural experience at a UK university. International Journal of Research \& Method in Education. 
this spatiotemporal space, she reflected several aspects of her becoming. She had become increasingly internationalised (as visualised by the change of the colour in the successive depictions of herself), and open to know (as visualised by the growing eyes in these same successive depictions of herself). Also, she had become more tolerant to differences. She imagined 'blank spaces' inside of her 'self' to 'welcome any colour to come to fill inside'. In the end, Jiajia created a person at the centre of the painting. This person, with particular qualities (e.g. openness, kindness, optimism, friendliness, and harmony), is who she wanted to become in intercultural communication. Jiajia told me that she did not have this person in mind at first. But it was the process of painting and imagining that enabled her to see and to know this person and her qualities.

In this section, I have used four example paintings to illustrate the rich insights that the students generated through the imaginative space of the arts. My analysis of these example paintings may not produce findings that generalise to wider populations. However, my intention is to use these example paintings to illustrate the rich data on students' meaning-making of intercultural experience that these generated, and then to explore imagination as a methodological source of knowledge, which I proceed to discuss below.

\section{Imagination as a methodological source of knowledge}

In the previous sections, I have introduced my understanding of the term imagination and the imaginative space provided by the arts, following which I have also exemplified actual students' insights enabled through the imaginative space of painting. As illustrated by the

Huang, Z. M. (2020). Exploring imagination as a methodological source of knowledge: Painting students' intercultural experience at a UK university. International Journal of Research \& Method in Education. 
example paintings, the students imagined a world of possibilities and meanings, an imaginative world that accommodates the confluence of their internal recognition of external reality. Based upon the students' subjective constructions of their intercultural experience, as mediated through the imaginative space of paintings, in this section I explore how imagination can provide a methodological source of knowledge for researchers. I discuss four benefits of imagination which can promote expansive, purposeful, fluid, and developmental knowledge for educational research.

First, imagination, as mediated by metaphors, enables associative and expansive knowledge for research. Through the associative and expansive power of imagination, individuals can see the links between otherwise independent things (e.g. cultures and bubbles), and create mental images of new possibilities beyond existence (Lakoff and Johnsen, 2003). In the example paintings, the students manipulated the meaning-associations through an imaginative network of symbols. They transferred and expanded their thinking across various domains of the mind (Modell, 2005; Voss, 2009). Through this expansive process of imagination, the students individually transcreated complex constructs (e.g. the bubble, and the fountain) of meanings about their intercultural experience.

Second, imagination, filled with intentionality, can encourage purposeful knowledge for research data generation. As individuals select and brings concepts together through imagination, their imagination reflects their subjective responsiveness and intentions to the external world (Stoetzler and Yuval-Davis, 2002). In the example paintings, the students 
individually chose to visualise the mental-images of some elements over others about their intercultural experience. Their imagination purposefully prioritised certain meanings according to their subjective existence and intentionality. In this way, imagination provides a subjective and purposeful source of knowledge for individuals to sustain a coherent and continuous existence of the 'self', extending from the past to the present, and across diverse trajectories of life experiences.

Third, imagination provides educational researchers an opportunity to capture the fluidity of thinking reflecting the instable, changing nature of human life. It can add a non-static dimension of knowledge to the two-dimensional, temporal, and static space of words (and/or images). For instance, Helios designed 'The fountain' with a non-static nature as he imagined the fluid mechanism of filtering and circulating. Ana realised the non-fixed, changing relationship between the two people as she imagined the instability of 'The bubble'. Jiajia developed knowledge about her becoming as she imagined about the mobility of her 'self' (e.g. movements and transformations) through time and space.

Fourth, imagination enables developmental and transcendental knowledge by bridging between the known and the unknown, consciousness and sub-consciousness, and existence and non-existence. Through the developmental and transcendental potential of imagination, humans can invent visions of alternative possibilities beyond the limits of the present reality (Bland, 2012; Reichling, 1990; Van Leeuwen, 2013). For instance, Ana developed her awareness beyond 'cultural differences' through her imagination about the layers, thickness, 
colour, and air of the bubbles in her painting. Ellyn could critique stereotyping by imagining a distorted vision of how others are perceived. Helios and Jiajia developed an understanding of their own becoming through various, individualised imaginations about their transcendental processes. Imagination, thus, provides educational researchers an opportunity to capture developmental and transcendental processes of becoming (to know, and to be).

With the potential for expansiveness, purposefulness, fluidity, and development, imagination provides a rich methodological source of knowledge for educational research. It can be particularly effective for understanding the subjective realities (e.g. perspectives, experiences, learning and relationships) constructed by students, teachers, or parents. For instance, imagination can be used to research topics about sub-consciousness, awareness and development, (trans)formation of identity and personhood, negotiation of interpersonal and (inter)cultural dynamics, and learning of values and thinking skills in various educational settings (Egdar, 2004, 142).

However, the powerful faculty of imagination is usually marginalised and overlooked in educational research (Jones et al., 2008, 4; Egdar, 2004). Sameshima, Wiebe and Hayes (2019) argue that imagination is a 'theoretically innovative post-qualitative method' which enables relational and 'gap-filling' (Vygotsky, 2004) constructions of new knowledge and new questions. Imagination, mediating between the known and the unknown (Thomas, 2019, 155), unleashes transcendental, subjectively-meaningful exploration of reality. It challenges our understanding of consciousness and pushes the boundaries of thinking - for example, by 
challenging the dominance of the traditionally-privileged sources (e.g. rationality, 'scientific' measurements, and language) of knowledge. Imagination can, therefore, contribute to extending our understanding of what counts as knowledge and how knowledge is produced for educational research.

\section{Concluding comments}

This paper has explored imagination as a methodological source for researchers to enable expansive, purposeful, fluid and developmental knowledge for understanding the subjective realities constructed by individuals. Based on a small-scale, exploratory study, I have discussed four benefits of imagination for educational research. First, imagination can enable associative, expansive knowledge by creating links between independent things (e.g. as exemplified by Ana's discussion about 'culture' and 'bubble') and constructing new possibilities beyond what is known. Second, imagination, filled with purposefulness and intentionality, can generate selective and coherent knowledge about individuals' construction of subjective realities. Third, imagination adds a non-static, fluid life to the subjective constructions (e.g. as exemplified in Helios' design of the filtering and circulating mechanism of the 'fountain', and in Jiajia's movements and transformation of the 'self' through time and space). Last but not least, imagination enables developmental and transcendental knowledge by mediating between the known and the unknown, consciousness and sub-consciousness, and existence and non-existence (e.g. in Ana's imagination of breaking the 'bubbles', in Ellyn's critique of stereotyping, and in Jiajia's becoming through the intercultural eye).

Huang, Z. M. (2020). Exploring imagination as a methodological source of knowledge: Painting students' intercultural experience at a UK university. International Journal of Research \& Method in Education. 
By adopting the methodology of imagination, educational researchers can facilitate a post-qualitative, thinking space of experimentation through which knowledge are transcreated and demonstrated by individuals as meaning-makers. Such knowledge - as expansive, purposeful, fluid, and developmental by nature - can be conceptually-abstract and structurally-complex, which, thus, may not be immediately expressible or interrogatable in a coherent way through the use of traditional research methods (such as questionnaires and interviews). The methodology of imagination can be particularly useful for researchers to develop understandings about the construction of subjective realities (e.g. students' intercultural learning, the development of intercultural personhood, or the negotiation of relationship with cultural 'others'), or the role of a particular concept at play in such subjective constructions (e.g. how mindfulness can play a role in students' meaning-making of their intercultural experience) (Huang, 2019).

My exploration contributes to pushing the epistemological and methodological boundaries of what counts as knowledge and how knowledge is produced for educational research. More research is needed in order to provide a comprehensive theoretical account of imagination, and to further develop imagination-based instruments. Specifically, more needs to be done to understand the nature of imagination as a methodological source of knowledge for education research, and how imagination may be facilitated by various arts-based methods and possibly other educational research methods. The present paper is a step in this direction, providing a detailed analysis of two variations of painting (i.e. cartoon- and freestyle- painting), thereby illustrating how Arts-based Educational Research (ABER) may 
be adopted to facilitate imagination as a methodological source of knowledge for educational research.

Huang, Z. M. (2020). Exploring imagination as a methodological source of knowledge: Painting students' intercultural experience at a UK university. International Journal of Research \& Method in Education. 


\section{References}

Armitage, A. 2012. “A Methodology of the Imagination.” Journal of Business Administration Research 1 (1): 1-12.

Barrow, R. 1988. "Some Observations on the Concept of Imagination." In Imagination and Education, edited by K. Egan and D. Nadaner, 79-90. New York: Teachers College Press.

Barth, J. R. 2001. The Symbolic Imagination: Coleridge and the Romantic Tradition. New York: Fordham University Press.

Barone, T. 2006. “Arts-based Educational Research Then, Now, and Later.” Studies in Art Education 48 (1): 4-8.

Barone, T., and Eisner, E. 1997. “Arts-based Educational Research.” Complementary Methods for Research in Education 2: 75-116.

Barone, T. and Eisner, E. 2006. “Arts-based Educational Research.” In Handbook of Complementary Methods in Education Research, edited by L. Green, G. Camilli, and P. B. Elmore, 95-110. Washington, D.C.: the American Educational Research Association by Lawrence Erlbaum Associates, Inc.

Bauer, A., Franklin, J., Gruschow, S., and Dowshen, N. 2019. "Photovoice: Empowering Transgender and Gender-expansive Youth”. Journal of Adolescent Health 64 (2): S5.

Bland, D. 2012. “Analysing Children's Drawings: Applied Imagination.” International Journal of Research \& Method in Education 35 (3): 235-242.

Bolton, N. 1982. "The Lived World: Imagination and the Development of Experience." Journal of Phenomenological Psychology 13(1): 1.

Boyce, G., and Greer, S. 2013. "More than Imagination: Making Social and Critical Accounting Real.” Critical Perspectives on Accounting 24 (2): 105-112.

Edgar, I. 2004. A Guide to Imagework: Imagination-based Research Methods. London: Routledge. 
Eisner, E. 2006. "Does Arts-based Research Have A Future?" Studies in Art Education 48 (1): 9-18.

Eve, P. H. D. 2015. "Imagination as a Vehicle to Reality." International Journal of English: Literature, Languages and Skills 4 (2): 30-35.

Dobbs, S. M. 1998. Learning in and through Art: A Guide to Discipline-based Art Education. California: Getty Publications.

Dryden, D. 2004. "Memory, Imagination, and the Cognitive Value of the Arts." Consciousness and Cognition 13 (2):254-267.

Epstein, R. 2004. "Consciousness, Art, and the Brain: Lessons from Marcel Proust." Consciousness and Cognition 13: 213-243.

Glas, G. 2006. "Person, Personality, Self, and Identity: A Philosophically Informed Conceptual Analysis.” Journal of Personality Disorders 20 (2): 126-138.

Gokbulut, Y., and Kus, S. 2019. "Cartoon to Solve Teaching Problem on Mathematics." International Journal of Evaluation and Research in Education 8 (1): 145-150.

Halpin, D. 2007. “Utopian Spaces of 'Robust Hope': The Architecture and Nature of Progressive Learning Environments.” Asia-Pacific Journal of Teacher Education 35 (3): $243-55$.

Hanson, K. 1988. "Prospects for the Good Life: Education and Perceptive Imagination.” In Imagination and Education, edited by K. Egan and D. Nadaner, 128-40. New York: Teachers College Press.

Holliday, A. 2000. "Culture as Constraint or Resource: Essentialist Versus Non-essentialist Views." IATEFL Language and Cultural Studies SIG 18: 38-40

Huang, Z. M. 2017. "Multislicing Semiotic Analysis (MSA): Engaging with the Meanings of Creative-visual-arts Data.” In Building Intercultural and Interdisciplinary Bridges: Where Theory Meets Research and Practice, edited by P. Burnard, V. Ross, H. J. Minors, K. Powell, T. Dragovic, and E. Mackinlay, 104-112. Cambridge: BIBACC Publishing. 
Huang, Z. M. 2019. "Mindfulness and Intercultural Personhood: Using Creative-visual-arts to Understand Students' Meaning-making about Their Intercultural Experience at a UK University." PhD. thesis, The University of Manchester.

Iheoma, E. O. 1993. "Vico, Imagination and Education.” Journal of Philosophy of Education 27 (1): 45-55.

Jones, R., Clarkson, A., Congram, S., and Stratton, N. eds. 2008. Education and Imagination: Post-Jungian Perspectives. London: Routledge.

Kamhi, M. M., and Torres, L. 2000. "Critical Neglect of Ayn Rand's Theory of Art.” The Journal of Ayn Rand Studies 1-46.

Kanno, Y., and Norton, B. 2003. "Imagined Communities and Educational Possibilities: Introduction.” Journal of Language, Identity and Education 2 (4): 241-249.

Kant, I. 2000. Critique of the Power of Judgment. Cambridge: Cambridge University Press. Kast, V. 2014. “Complexes and Imagination.” Journal of Analytical Psychology 59 (5): 680-694.

Keightley, E., and Pickering, M. 2012. “The Mnemonic Imagination.” In The Mnemonic Imagination: Remembering as Creative Practice, edited by E. Keightley and M. Pickering, 43-80. Palgrave Macmillan, London.

Kind, A., and Kung, P., eds. 2016. Knowledge through Imagination. Oxford: Oxford University Press.

Lakoff, G., and Johnson, M. 2003. Metaphors We Live by. Chicago: University of Chicago. Lambert, J., and Usher, A. 2013. Internationalization and the Domestic Student Experience. Toronto, ON: Higher Education Strategy Associates.

Langer, S. K. 1953. Feeling and Form. New York: Scribner's publish.

Li, C. 2009. “想象一词与大象有关吗?” [“Is the Word ‘Imagination’ Related to Elephant?”] 中国少年文摘 [Chinese Youth Journal] (18): 21-21.

McNiff, S. 2012. "Opportunities and Challenges in Art-based Research.” Journal of Applied Arts and Health 3 (1): 5-12.

Modell, A.H. 2003. Imagination and the Meaningful Brain. Cambridge, MA: MIT Press.

Huang, Z. M. (2020). Exploring imagination as a methodological source of knowledge: Painting students' intercultural experience at a UK university. International Journal of Research \& Method in Education. 
Modell, A.H. 2005. "Emotional Memory, Metaphor, and Meaning.” Psychoanalytic Inquiry 25 (4): 555-568.

Newsome, L. K., and Cooper, P. 2016. 'International Students' Cultural and Social Experiences in a British University: 'Such a Hard Life [It] is Here'.” Journal of International Students 6 (1): 195-215.

Pelaprat, E., and Cole, M. 2011. “"Minding the gap': Imagination, creativity and human cognition." Integrative Psychological and Behavioural Science 45 (4): 397-418.

Reichling, M. J. 1990. "Images of Imagination.” Journal of Research in Music Education 38 (4): 282-293.

Sameshima, P., Wiebe, S., and Hayes, M. T. 2019. "Imagination: The Generation of Possibility." In Perspectives on Arts Education Research in Canada, Volume 1, edited by B. W. Andrews, 19-35. Leiden: Brill Sense.

Schweisfurth, M., and Gu, Q. 2009. "Exploring the Experiences of International Students in UK Higher Education: Possibilities and Limits of Interculturality in University Life.” Intercultural Education 20 (5): 463-473.

Singer, M. R. 1998. "The Role of Culture and Perception in Communication.” Culture, Communication and Conflict: Readings in Intercultural Relations 2: 28-52.

Sinner, A., Leggo, C., Irwin, R. L., Gouzouasis, P., and Grauer, K. 2006. “Arts-Based Educational Research Dissertations: Reviewing the Practices of New Scholars.” Canadian Journal of education 29 (4): 1223-1270.

Stevenson, L. 2003. "Twelve Conceptions of Imagination.” The British Journal of Aesthetics 43 (3): $238-259$.

Stoetzler, M., and Yuval-Davis, N. 2002. "Standpoint Theory, Situated Knowledge and the Situated Imagination." Feminist Theory 3 (3): 315-333.

Sullivan, G. 2008. "Painting as Research: Create and Critique." In Handbook of the Arts in Qualitative Research: Perspectives, Methodologies, Examples, and Issues, edited by J. G. Knowleds and A. L. Cole, 239-250. Thousand Oaks: Sage Publications, Inc. Sullivan, G., ed. 2010. Art Practice as Research: Inquiry in Visual Arts. London: Sage.

Huang, Z. M. (2020). Exploring imagination as a methodological source of knowledge: Painting students' intercultural experience at a UK university. International Journal of Research \& Method in Education. 
Thomas, A. 2019. "Imagination." In Keywords in Radical Geography: Antipode at 50, edited by V. Gidwani and S. Chari, 155-158. Oxford: Wiley Blackwell.

Van Leeuwen, N. 2013. “The Meanings of "Imagine” Part I: Constructive Imagination.” Philosophy Compass 8 (3): 220-230.

Voss, A. 2009. "A Methodology of the Imagination." Eye of the Heart: A Journal of Traditional Wisdom 3: 37-52.

Vygotsky, L. S. 2004. "Imagination and Creativity in Childhood." Journal of Russian and East European Psychology 42 (1): 7-97.

Walton, K. 1990. Mimesis as Make-Believe. Cambridge MA: Harvard University Press.

Warnock, M. 1976. Imagination. Los Angeles: University of California Press.

Warwick, D., and Purdy, N. 2019. "Cartoons as Visual Representations of the Development of Primary School Children's Understanding of Bullying Behaviours." Pastoral Care in Education 37 (3): 1-19.

Huang, Z. M. (2020). Exploring imagination as a methodological source of knowledge: Painting students' intercultural experience at a UK university. International Journal of Research \& Method in Education. 